\title{
Hidrocarburos no convencionales y fracking: Estado, empresas y tensiones territoriales en la Patagonia argentina
}

\author{
Unconventional hydrocarbons and fracking: State, companies and \\ territorial tensions in Argentine Patagonia
}

\section{Juan Antonio Acacio * y Fernando Svampa **}

\section{PALABRAS CLAVE}

Territorio

\section{Extractivismo}

Fracking

\begin{abstract}
* Instituto de Investigaciones en Humanidades y Ciencias Sociales- Facultad de Humanidades y Ciencias de la Educación, Universidad Nacional de La Plata / CONICET, Argentina | acaciojuan89@gmail.com

** Facultad de Ciencias Sociales, Universidad de Buenos Aires; Universidad Nacional de Río Negro, Sede Andina, Argentina I correosyenviossvampa@gmail.com
\end{abstract}

\section{RESUMEN}

En el presente trabajo buscamos abordar los cambios en los territorios donde se han instalado recientemente los emprendimientos para la extracción de Hidrocarburos de Reservorios No Convencionales (HRNC). En ese sentido puntualizamos en el accionar del Estado en sus distintos niveles, y de las empresas que intervienen en los proyectos que se llevan a cabo en la Provincia de Neuquén y en la Provincia de Rio Negro. Buscamos así dar cuenta de la tensión de territorialidades en torno a otras actividades productivas, al cuidado del medio ambiente, la ocupación de territorios y al impacto urbano que trae aparejada la instalación de estas actividades.

\section{KEYWORDS}

Territory

Extractivism

Fracking

\section{ABSTRACT}

In this work we seek to approach, the changes in the territories where the ventures for the extraction of Hydrocarbons from Non - Conventional Reservoirs (HRNC) have recently been installed. In that sense, we point out in the actions of the State in its different levels, and of the companies that take part in the projects that are carried out in the Province of Neuquén and in the Province of Rio Negro. We are thus aware of the tension of territorialities around other productive activities, the care of the environment, the occupation of territories, and the urban impact that entails the installation of these activities.

Fecha de recibido: 12/06/2017 | Fecha de aceptado: 24/08/2017 | Fecha de publicado: 28/12/2017 


\section{Introducción}

Desde el comienzo de la utilización de combustibles fósiles para el desarrollo de las sociedades, las emisiones de dióxido de carbono emitidas a la atmósfera han aumentado a niveles exorbitantes, causando -entre otros efectos- el aumento en la temperatura del planeta. Son numerosos los estudios que coinciden en pensar que hemos ingresado al Antropoceno, término acuñado por Paul Kruzten en el año 2000, que marca la entrada a una nueva época geológica, en la que el hombre aparece como una fuerza con capacidad de transformación de alcance global (Svampa, 2016).

El capitalismo global, fuertemente estratificado y con diferentes grados de responsabilidades e impactos de sus distintas sociedades e individuos, ha alterado el sistema ecológico global, el funcionamiento del clima de la Tierra, la composición y características de sus ríos, mares, océanos y hasta el propio paisaje.

Nos encontraríamos entonces de cara al problema de los límites civilizatorios, en el marco de un planeta finito y humanamente modificado, que exige la necesidad de pensar desde otras bases la relación entre sociedad y naturaleza, entre economía y política, entre producción, circulación y consumo de bienes (Svampa, 2016, p. 19).

En la Argentina, la dependencia en los combustibles fósiles está intrínsecamente relacionada con los regímenes sociales de acumulación, con factores territoriales, demográficos, económicos e institucionales que inciden en las actividades microeconómicas de generación de ganancias y toma de decisiones de inversiones. La economía argentina se caracteriza por ser estructuralmente heterogénea, con la coexistencia de sectores económicos con importantes diferencias en términos de productividad del trabajo, aplicación de capital y organización del proceso productivo; manteniendo significativas brechas de productividad entre establecimientos y sectores, derivado de la acotada disponibilidad de tecnología y capital al interior de las economías nacionales (Prebisch, 1949; Pinto, 1968; Di Filippo y Jadue, 1976). La concentración paulatina de las técnicas productivas "modernas" en una gama reducida de actividades -generalmente orientadas a la exportación de bienes demandados por el mercado internacional- ha conllevado a un aislamiento creciente de los sectores económicos más tecnológicamente desarrollados respecto del resto de la estructura productiva y, en el marco de economías periféricas y semiperiféricas en América Latina, ha acotado las fuentes de divisas necesarias para la expansión de otras actividades que absorban fuerza de trabajo. En este sentido, para la Argentina, el perfil característico de inserción de su economía al mercado global ha fortalecido la dependencia de la naturaleza en el marco de la división internacional del trabajo, ya sea en su forma tradicional o a partir de nuevos recursos tecnonaturales (Escobar, 1997; Lander, 1993). La profundización de estas dinámicas de acumulación económica y modelos de desarrollo han propiciado la aparición de categorías críticas como extractivismo o neoextractivismo. Gudynas (2011) propone el concepto de neoextractivismo para afirmar diferencias con el extractivismo "tradicional”, considerando que existe un neoextractivismo "progresista”, en el que los Estados tienen un papel más activo. Según Svampa (2011), el concepto de neoextractivismo refiere en primer lugar al patrón de acumulación sustentado en la sobreexplotación de recursos naturales que son cada vez más escasos. En segundo lugar, el neoextractivismo está dirigido a la exportación de bienes primarios, como hidrocarburos, metales, minerales, productos agrarios y biocombustibles. Una tercera característica es la envergadura de los emprendimientos y las inversiones económicas, 
con actividades de capital-intensivo y la presencia de grandes corporaciones transnacionales. En último lugar, el neoextractivismo implica una dinámica territorial orientada a la ocupación intensiva del territorio, generando desplazamientos de actividades regionales y formas de vida. Esto ha traído aparejado el incremento de las luchas por el territorio, ya sea de la mano de movimientos indígenas y campesinos, como de movimientos urbanos autonomistas, que centran su demanda en la defensa de los recursos naturales y/o bienes comunes, la biodiversidad y el ambiente.

Cabe remarcar que este trabajo se sitúa en el marco más amplio de nuestro trabajo de investigación doctoral, que se encuentra en etapas iniciales. De esta manera, el texto intentará ser una primera reflexión, un acercamiento a la temática de interés que nos permitirá posteriormente ahondar en las cuestiones que nos resultan pertinentes para nuestras investigaciones. La intención del trabajo es realizar una aproximación cualitativa a la problemática de la explotación de hidrocarburos no convencionales en vinculación con el territorio. Para realizar dicha aproximación se hará uso de información proveniente de fuentes que permiten ahondar -para la Cuenca Neuquina- en la trayectoria de YPF en Vaca Muerta a partir del 2012. Nos valemos de informes oficiales y de agencias especializadas en la problemática, como declaraciones públicas de organizaciones y movimientos sociales. También se emplearán fragmentos de las primeras entrevistas semiestructuradas, realizadas para retratar la situación de los chacareros en el municipio de Allen en la Provincia de Río Negro. $\underline{1}$

En un primer apartado indagaremos en torno a la situación energética argentina, para entender la apuesta política y/o económica que se realiza en torno a la explotación de hidrocarburos de reservorios no convencionales (HRNC). En un segundo apartado analizaremos el escenario actual de los proyectos de explotación de hidrocarburos no convencionales en la Cuenca Neuquina y en el Alto Valle de Río Negro, enfocándonos en el rol y las estrategias adoptadas por el Estado provincial y nacional, por las grandes operadoras -principalmente YPF- y las PyMEs que son las proveedoras de las grandes operadoras en la producción hidrocarburífera. En el tercer apartado daremos cuenta de la tensión de territorialidades que surge en torno al fracking, describiendo las consecuencias territoriales, socioeconómicas y los conflictos socioambientales inherentes a la actividad en la localidad de Allen, en Rio Negro, y en la Provincia de Neuquén.

\section{Problemática energética en Argentina}

Luego de que transcurriera la crisis del 2009, que marcó un descenso en el consumo energético global, en el año 2010 se registró un crecimiento pronunciado. Este aumento fue influenciado fuertemente por China, que aumentó su demanda energética superando a Estados Unidos. En el caso de América Latina (excluyendo a México y Chile) el aumento del consumo de energía en el año 2010 fue del 5,1\% respecto al año 2009. Entre el 2000-2010, el consumo energético en la región aumentó un 32\%. Brasil es el mayor consumidor de energía (41\%), seguido por Venezuela (14\%) y Argentina (12\%). La fuente más utilizada es el petróleo (46\%), seguido por la hidroelectricidad (25\%), el gas natural (22\%) y en menor medida el carbón (4\%) (Honty, 2013). La Agencia Internacional de la Energía, en su informe "Prospectiva Mundial de la Energía”, sostiene que en el futuro "la producción de crudo convencional alcanza un nivel casi estable de 68-69 millones de barriles diarios (mb/d), pero sin llegar a su pico histórico de 70 mb/d alcanzado en 2006”. Al haber 
alcanzado su pico la explotación de hidrocarburos convencionales, el crecimiento esperado de la oferta (15 mb/d al 2030) provendrá del llamado petróleo "no convencional”, que se extrae mediante la técnica de la fractura hidráulica o fracking. 2

Ahora bien, en Argentina encontramos una matriz altamente dependiente de los combustibles fósiles. La política económica del Estado en relación a los hidrocarburos de yacimientos no convencionales se desarrolla en un contexto local caracterizado por el incremento del consumo energético y la caída de la extracción de gas y petróleo de yacimientos convencionales. Recordemos que en la Argentina, debido a un acelerado crecimiento en el periodo 2003-2014, se generó un fuerte aumento de la demanda de energía. Para satisfacerla, se optó por invertir en centrales de generación térmica, que funcionan a base de gas, sin promover la producción nacional de este último. Esto generó que a partir de 2004 se perdiera la capacidad de autoabastecimiento, acrecentando la importación de gas, gasoil y fueloil, principalmente de Bolivia. El aumento del consumo energético se debió no sólo a la industria, sino también al aumento de la demanda de los hogares, producto de una mayor inclusión social y la recuperación del salario real, como así también a un nivel de derroche, particularmente en hogares de ingresos medios y altos de la ciudad de Buenos Aires y partidos del conurbano bonaerense.

En el 2004 se implementó el Plan Energético Nacional, cuya meta era dirigir las inversiones de origen estatal para el período 2004-2019, expandiendo la estructura energética, para aumentar de esta manera la potencia instalada de los equipos de generación (que incluye la construcción de nuevas centrales eléctricas), desarrollar formas renovables de energía y reactivar el Plan Nuclear Argentino. Dicho plan busca también incrementar la interconexión de energía eléctrica y distribución de gas natural, como así también la exploración y explotación de fuentes hidrocarburíferas.

En este sentido, la apuesta de la Argentina por la explotación de HRNC, si bien viene en sintonía con la agenda propuesta por los Estados Unidos, se enmarca en una coyuntura local de incremento del consumo energético y de la caída de la extracción de gas y petróleo en yacimientos convencionales. Según información de la Ex Secretaría de Energía y el Instituto de Petróleo y Gas Natural (IAPG), el pico máximo de producción de petróleo se alcanzó en 1996, y el del gas en el 2006. Desde aquel momento, la producción cayó en un 32\% para el caso del petróleo y un 20\% para el gas natural, evidenciado una disminución continua para el decenio 2004-2014 (Recalde, 2016). La caída en las reservas comprobadas de hidrocarburos convencionales, como así también la caída en la producción y la reducción del autoabastecimiento energético, se produjo por la sobre explotación de los yacimientos con fines de exportación en el período de los noventa, con la privatización del sector petrolero en Argentina (Recalde, 2011a). Entre 1995 y 2003, el número de pozos exploratorios perforados para hidrocarburos convencionales se redujo un 87\% (Recalde, 2016). En este sentido, las peculiaridades de la caída de las inversiones del sector petrolero, parecerían estar acompañadas por los desequilibrios y debacles institucionales en el corto y largo plazo. Por lo tanto, las debilidades de los contratos petroleros y gasíferos en un marco de desregulación y privatización del sector, como la caída de los precios internacionales del petróleo y sus repercusiones en el precio del gas natural, fueron impactando en las inversiones de exploración. 


\section{Nuevas apuestas a los hidrocarburos no convencionales. Empresas y Estado en el nuevo escenario}

En un contexto de declinación probada de las reservas de recursos fósiles a nivel planetario, un informe de la Energy Information Agency de Estados Unidos llamó la atención sobre la posibilidad de explotar los HRNC, dispersos a nivel global, hallando en dicho país del norte formaciones geológicas ricas en estos recursos. En el informe Argentina se posicionó en el ranking mundial de reservas de shale oil y tight gas, ubicados sobre todo en la formación de Vaca Muerta, que atraviesa las provincias de Neuquén, Rio Negro, La Pampa y Mendoza.

\section{Mapa No 1. Región de Vaca Muerta.}

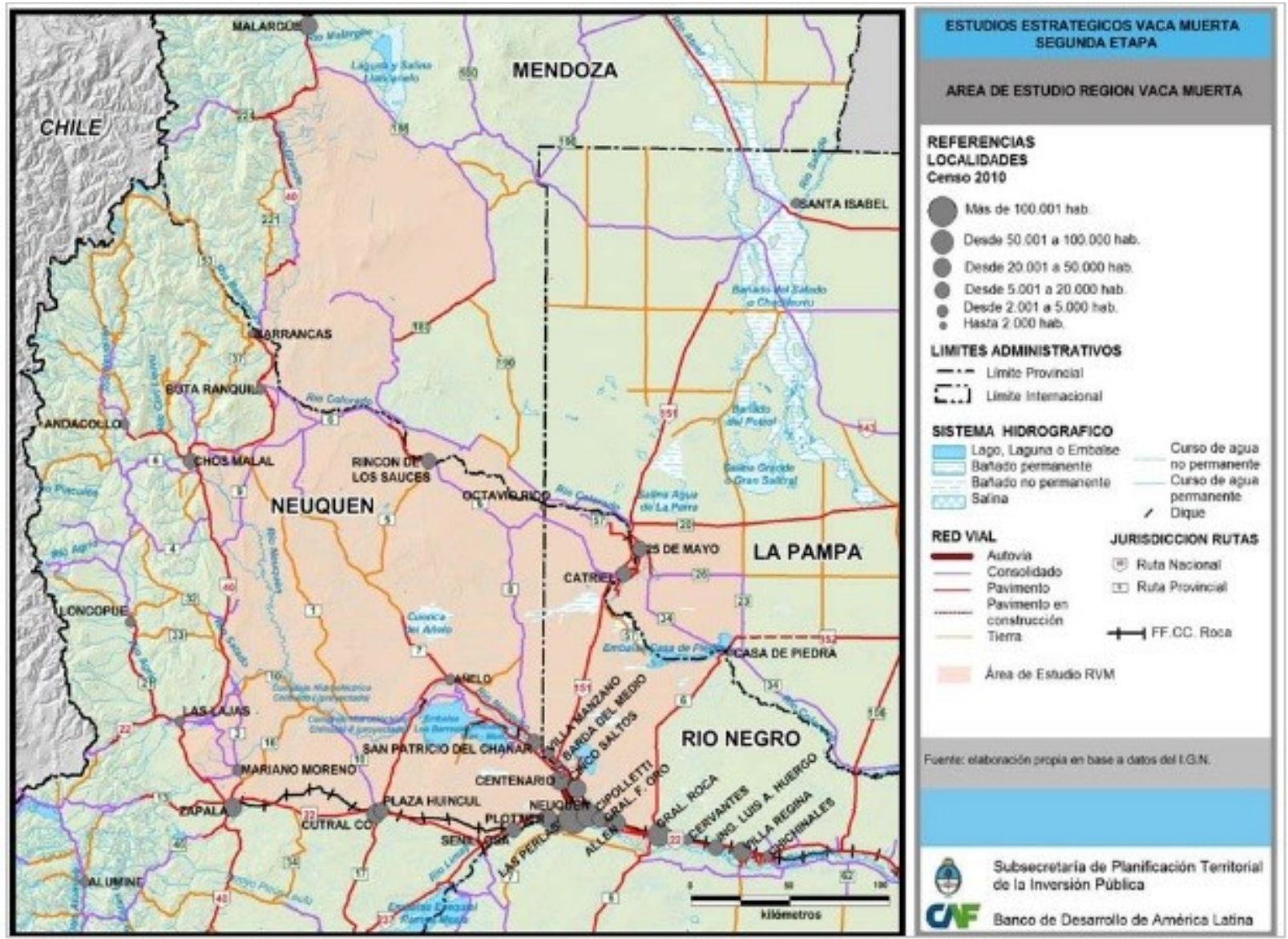

Fuente: Subsecretaria de Planificación Territorial de la Inversión Pública, 2015.

La explotación de yacimientos no convencionales se constituyó en una posibilidad para el gobierno de hacer frente a la endeble situación energética y el descenso de los niveles de extracción de gas y petróleo convencionales. La política energética se concretó a partir de la expropiación, por parte del Estado Nacional, del 51\% de las acciones de YPF S.A. al grupo español Repsol, en el año 2012. El gobierno kirchnerista apostó fuertemente a la alianza con ciertas empresas poseedoras del knowhow necesario para la extracción de estos recursos. El impulso dado a las tecnologías no convencionales se desarrolló bajo la influencia de empresas multinacionales tratando de evitar (por parte del Estado y las empresas privadas) el debate en la arena pública, facilitado por la gran aceptación social que traía aparejada la recuperación de una empresa que posee un lugar central en 
el imaginario social argentino. Para ello, el gobierno apeló a un discurso épico (Svampa y Viale, 2014) que ponía en el centro la cuestión de la soberanía energética, y la necesidad de recuperación de los niveles históricos de extracción de hidrocarburos para el abastecimiento energético, asociando soberanía hidrocarburífera a soberanía energética, dejando fuera la discusión por alternativas para cambiar la composición de la matriz energética.

Después de la mencionada recuperación de YPF S.A. se aprobaron los lineamientos que seguiría la compañía a través del “Plan Quinquenal 2013-2017”. En este marco, el eje principal de la política de la empresa consiste en lograr un crecimiento sostenido y rentable que genere valor para los accionistas. YPF S.A es una empresa mixta con mayoría de participación estatal, bajo la forma de una Sociedad Anónima; por ende, es llamativo que una empresa de mayoría estatal posea como objetivo de base, lineamientos comparables a una empresa privada (Arelovich et al., 2015). Así, las sociedades anónimas operan bajo el marco del Derecho Privado, por lo que conforman su patrimonio por acciones individuales que cotizan en bolsa (Tagliabue, 2013). En este sentido, la estructura societaria limita los objetivos que presenta una empresa estatal, reduciéndola al carácter privado. Estructurado en etapas, la primera instancia del Plan Estratégico, denominado de Alto Impacto 2012-2013, tuvo como objetivo detener la declinación de la producción por medio de una inversión de U\$S 1.700 millones en el desarrollo de la exploración y puesta en producción de pozos de shale gas y oil. En la segunda etapa 2013-2017 se pretende llegar a una inversión de U\$S 37.200 millones en términos brutos, contando a los socios del sector hidrocarburíferos. $\underline{3}$ Del total se destinarán U\$S 19.600 millones para elevar la extracción de petróleo, U\$S 6.500 millones para aumentar la extracción de gas y U\$S 8.000 millones para incrementar la capacidad instalada (Arelovich et al., 2015).

La empresa YPF S.A. ha construido acuerdos con diversas firmas de capitales extranjeros para la explotación de HRNC en la Cuenca Neuquina. Al constituir un activo de clase mundial, los intereses en pugna comprenden a grandes empresas operadoras transnacionales (Chevron, Total, Exxon Mobil, Shell, BP, CNOOC), estatales (YPF, Petronas, GyP) y nacionales (Pluspetrol, Tecpetrol) (Mullally et al., 2017), y la misma división se aplica a empresas de servicios, donde las internacionales Schlumberger, Halliburton y Baker Hughes concentran una parte sustancial del negocio. Dentro de este último segmento también es importante contar a las firmas locales. En este marco, en julio de 2013 se concretó el Proyecto de Inversión con Chevron, con la finalidad de explotar HRNC en Loma La Lata Norte y Loma Campana (Neuquén), contemplando la perforación de más de diez pozos, con un desembolso por parte de Chevron de U\$SS 1.240 millones. ${ }^{4}$ A partir del 2014, luego de las pruebas pilotos, se firmaron acuerdos de inversión para tareas conjuntas en el área de Chihuido de la Sierra Negra Sudeste-Narambuena (Neuquén), con una proyección de perforación de 1.500 pozos y una inversión estimada de U\$S 15.000 millones para el 2017. Otro acuerdo con una gran empresa fue en el 2013, con Dow Europe Holding B.V y PBB Polisur S.A, por un monto de U\$S 188 millones para la explotación de HRNC en El Orejano (Neuquén). También se firmaron acuerdos el 28 de agosto del 2014 con Petronas (E\&P) Overseas Ventures Sdn Bhd, a través de una inversión en conjunto de U\$S 550 millones en el área de La Amarga Chica (Neuquén). El 6 de noviembre del 2013, YPF concreta otro acuerdo con Petrolera Pampa S.A para invertir U\$ 4.151.5 millones a cambio del 50\% de la participación en el área Rincón del Mangrullo 
(Neuquén), para explotar HRNC (Arelovich et al., 2015). Según Neuman (2012), más del 90\% de las empresas proveedoras de bienes y servicios a la actividad hidrocarburífera son PyMEs de capital nacional, $\underline{5}$ alrededor de 500 son las que operan en Neuquén en forma independiente o como subcontratistas (Landriscini, 2016). Esta nueva dinámica que surge a partir del 2012 se concretó en acciones como el Programa Sustenta de YPF, $\underline{6}$ que surgió como una política de desarrollo de proveedores, asociado al Instituto Nacional de Tecnología Industrial. Construyó ligazones con las universidades nacionales y con YPF Tecnología, en sintonía con las PyMEs en Neuquén. Estas acciones han significado la articulación con el Banco Nación, el Fondo Tecnológico Argentino, el Fondo Fiduciario para la Promoción de la Industria del Software, destacándose objetivos ligados a los nuevos negocios y mercados, como la adopción tecnológica para las PyMEs, el ascenso en la cadena, y en el conocimiento acumulado por la conectividad de agentes. En el último tiempo, el descenso operado en el precio internacional del petróleo crudo viene obligando a las operadoras a incrementar los accionarios microeconómicos y sectoriales dirigidos a aumentar la eficiencia, como así también los programas de flexibilización laboral. En este sentido, una de las principales dificultades que presentan estas empresas es el encuadre legal, ya que muchas de las PyMEs del sector servicio petrolero, ingeniería, obras civiles, productos metalmecánicos, electromecánica, transporte, instrumentos y comunicaciones, operan con montos de capital instalado y de facturación que superan los lineamientos de la escala que definen a empresas de nivel intermedio. Por otro lado, hay una notable heterogeneidad entre las proveedoras PyMEs, como sucede con la metalmecánica y la electrónica, con problemas de gestión de los contratos y prestación de los servicios, ineficiencias operativas de escala, de tiempo de pedido y entrega (Landriscini, 2016). En este contexto hay una destacada dinámica de creación, ampliación, fusión, absorción y desaparición de firmas en el sector, dependiente de las políticas macroeconómicas (como la tasa de interés y del valor del dólar) y sectoriales (precios, subsidios, tributación), como así también de los precios internacionales y las estrategias de empresas líderes.

\section{Las transformaciones territoriales en la Cuenca Neuquina}

La apuesta por la explotación de HRNC ha generado un considerable incremento de las inversiones en las zonas donde se encuentran dichos recursos. Donde se han instalado estos mega proyectos (OPSur, 2017) se ha desencadenado una serie relevante de movimientos y transformaciones a nivel territorial. Entendemos aquí el territorio de manera compleja, no solo como un mero soporte físico que contiene recursos naturales y población. Para Santos (1996) el territorio conforma un híbrido, formado de la unión indisociable de sistemas de objetos y sistemas de acción. Los sistemas de objetos o el espacio de la materialidad forman configuraciones territoriales donde la acción de los distintos sujetos se instala y crea un espacio propio. Así, el territorio es parte intrínseca de relaciones sociales, productoras pero a la vez producidas por la interrelación entre sujetos, pero también entre los sistemas de acción y sistemas de objetos, lo cual implica pensar que la misma constitución de un espacio como territorio se encuentra atravesada por relaciones de poder. 
Mapa No 2. Ubicación de pozos HRNC en Añelo y Allen. 2016

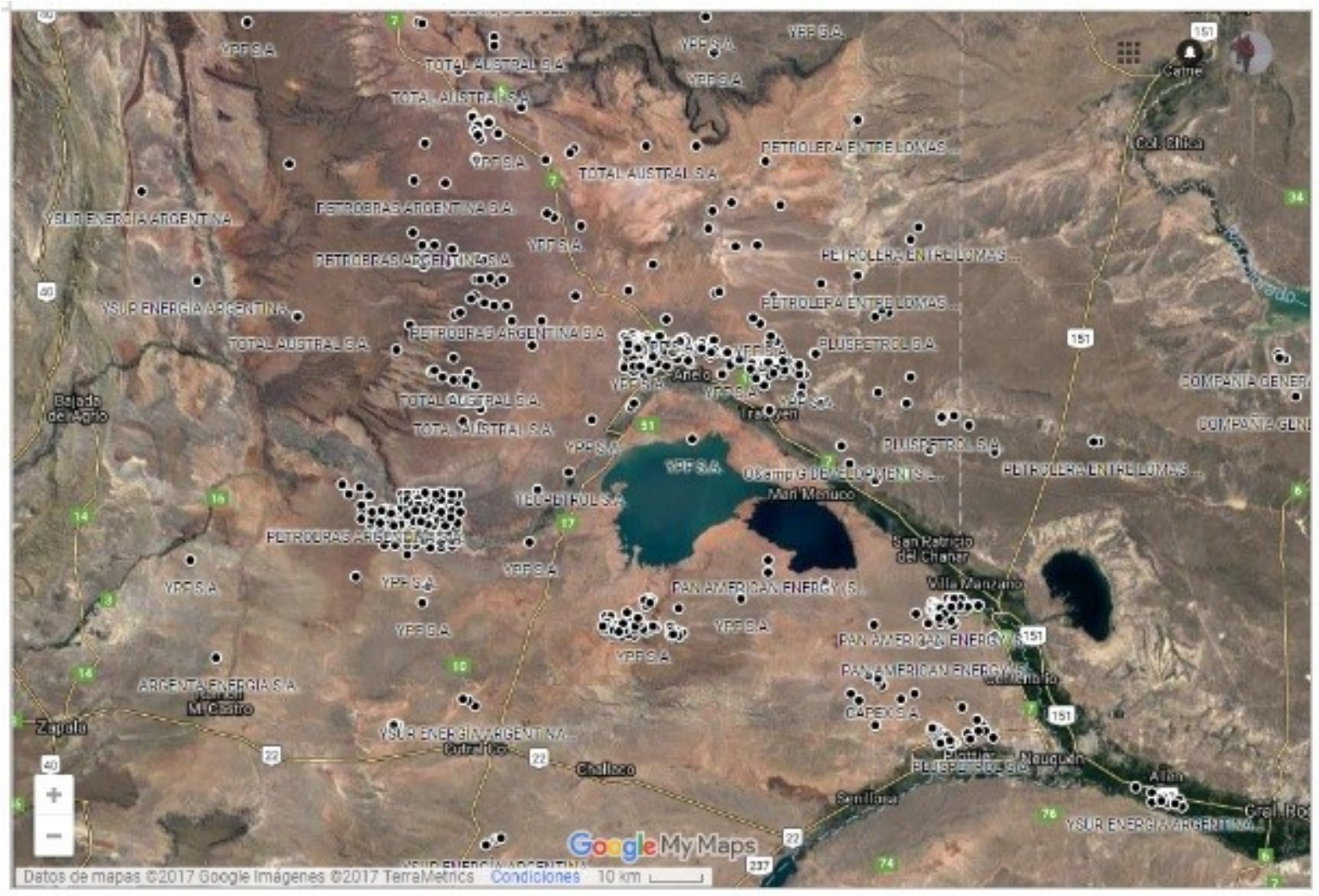

Fuente: Taller Ecologista de Rosario y Observatorio Petrolero Sur (2017). Boletín No 1 de julio. El mapa del fracking.

En este sentido, la producción del territorio como relación social no está exenta de relaciones de dominación y de pujas. Estas últimas se desarrollan en base a una correlación de fuerzas en la que los distintos sujetos tratan de imponer lógicas diferentes para definir un espacio como territorio, en donde entran en juego formas de apropiación de lo material, formas de significación sobre la tierra $\mathrm{y}$, por tanto, formas de entenderlo y de relacionarse con otros sujetos, y con diversas territorialidades presentes. Por lo tanto, la instalación de un megaproyecto desata, en el corto y largo plazo, un conjunto de cambios en la configuración de los territorios.

Frente a la instalación de grandes empresas y PyMEs, y con un Estado (provincial y nacional) que refuerza el carácter neoextractivo en las políticas económicas y energéticas, se alzan voces críticas que entienden que la explotación de HRNC implica un nuevo avance sobre el territorio que potencia e instala un nuevo campo de desigualdades. Los discursos críticos de las asambleas contra el fracking y de las comunidades indígenas toman como eje central el acceso al agua como un bien común, y la defensa del territorio como parte esencial de la identidad colectiva (Svampa, 2016). La multisectorial contra el fracking, conformada por ciudadanos, científicos, pobladores y comunidades indígenas, apelan a criticar el discurso de los gobiernos y las empresas que generan la ilusión del desarrollo o la visión eldoradista (Svampa, 2015), sin tener en cuenta factores como la contaminación de acuíferos, del aire y otros problemas que acarrea la matriz monoproductiva. Las críticas se refieren principalmente a la inequidad en el acceso a la tierra, a los servicios públicos, 
marginalidad socioeconómica y cultural, saqueo y ocupación de los territorios de comunidades indígenas, migración de la población rural expulsada a centros urbanos, crecimiento de los bolsones de la pobreza y precarización laboral, entre otras. Al indagar un poco más, se vislumbran una serie de tensiones territoriales que tienen que ver con las dinámicas desplegadas por el Estado a nivel provincial y nacional, y las empresas para el desarrollo de este megaproyecto. Estas tensiones surgen -a nuestro entender- en distintos planos que se encuentran interconectados.

El primer plano tiene que ver con el desarrollo de infraestructuras de servicios en centros urbanos cercanos a la actividad petrolera. La instalación de proyectos extractivos de gran magnitud implica, en instancias estatales, el desarrollo de una serie de acciones para absorber todos los cambios territoriales que el megaemprendimiento necesita. El capital petrolero requiere para su desenvoltura de una infraestructura de servicios para desempeñar la actividad, y necesita adaptar las urbanizaciones que van surgiendo en torno a los territorios explotados y a la población ingresante ${ }^{7}$. El informe de la Subsecretaría de Planificación Territorial de la Inversión Pública de la Nación estimaba que la provincia de Neuquén requeriría 88.000 viviendas para el primer quinquenio 20152019, pensando en 220.000 nuevos habitantes y una familia tipo de 2,5 personas. Asimismo, se deberían construir 66.667 viviendas para el segundo quinquenio, considerando los 200.000 nuevos habitantes y una familia tipo de 3 personas (SPTIP, 2014, p. 82). La desmesurada llegada de nueva población en busca de oportunidades en el mercado de trabajo también implica el avance en la incorporación de suelos rurales para la urbanización. El informe de desarrollo para Añelo alarma sobre el avance en el desmonte de chacras con fines de desarrollo urbanístico y para la instalación

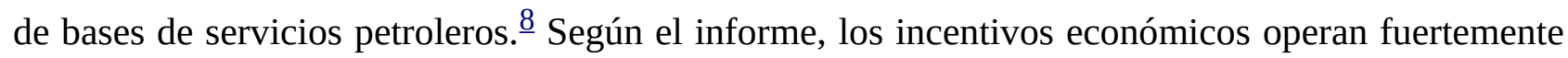
para la venta de terrenos que tradicionalmente se dedicaban a actividades agrícolas ganaderas. Por otro lado, nos encontramos con planes de infraestructura e ingeniería como el Proyecto Red Azul en la actualidad detenido-, una obra de grandes dimensiones ideada inicialmente para abastecer de agua al emprendimiento no convencional en la Cuenca Neuquina, buscando reducir los costos de explotación de los hidrocarburos no convencionales, ya que en términos de transporte y almacenamiento de agua las empresas realizan un gasto de aproximadamente diez millones de dólares. Asimismo, firmas como Servicios Ambientales de Neuquén, Ecopolo, Indarsa y Treater, se han instalado en las afueras de Añelo para ofrecer el servicio de tratamiento de residuos petroleros y de disposición final. Estas lógicas privadas de planificación ponen sobre el tapete la discusión acerca de la utilización del suelo y del agua en una zona con características desérticas. $\underline{9}$ En este sentido, los proyectos hidrocarburíferos buscan aprovechar los acuíferos superficiales, debido a la prohibición que rige para la utilización de aguas de napas freáticas de la provincia de Neuquén para las actividades petroleras. Estas cuestiones desatan una discusión de gran complejidad, sobre todo en el marco de la emergencia ambiental hídrica que atraviesa la misma provincia de Neuquén. La amplitud geográfica de Vaca Muerta y sus impactos supera en mucho los $30.000 \mathrm{~km} 2$ de la formación geológica. Con respecto a los activos y a las nuevas infraestructuras, la cadena de valor configurada en torno a Vaca Muerta va desde procesos necesarios y anteriores a la perforación, hasta la refinería, pasando por los ductos, los insumos específicos para cada etapa y las tratadoras de residuos (Mullally et al., 2017). Para la extracción de los hidrocarburos no convencionales por medio de la fractura hidráulica se requiere, además, de arena de silicio que se extrae de las canteras de las provincias de Entre Ríos y Chubut, generando así cambios que exceden a la formación 
geológica y los límites provinciales, convirtiendo a Vaca Muerta en un megaproyecto (OPSur, 2017).

La cuestión de las tensiones territoriales va más allá de la infraestructura y nos lleva a un segundo plano, hacia el campo de lo legal, lo jurídico y de los derechos. En este sentido, el avance de la frontera extractiva nos enfrenta a un escenario en donde los marcos legales se modifican y/o se avasallan para permitir la concreción de los proyectos extractivos (Svampa y Viale, 2014). Los distintos gobiernos, sin mucha distinción, empujan y promueven acuerdos y modificaciones legales para eximir a la fractura hidráulica de los requisitos y costos monetarios y ambientales que conlleva. Cabe recordar que, en el año 2013, el gobierno de la provincia de Neuquén sancionó el decreto N ${ }^{\circ}$ $422 / 13$, que constituye un desdibujamiento de las exigencias respecto de los requerimientos ambientales que las explotaciones de HRNC deberían cumplir para concretarse. Asimismo, el actual gobierno nacional de Mauricio Macri, a partir del 2016, alineado con empresas, sindicatos y el gobierno provincial de Neuquén, llevó a cabo un acuerdo para la flexibilización laboral que implica una reducción de costos, y de esa manera hacer más rentable la explotación no convencional en Vaca Muerta. $\underline{10}$

Las principales tensiones en Neuquén se desatan tanto por la apropiación del territorio, como por la cuestión de los recursos acuíferos. En cuanto a los territorios ancestrales indígenas, el Estado provincial y nacional, en conjunto con las empresas, trasgreden la normativa vinculada a los derechos indígenas, como el reconocimiento de la preexistencia étnica y cultural de los pueblos indígenas, e incumplen la normativa que exige consulta previa e informada del convenio 169 de la OIT (Svampa y Viale, 2014). El campo de lo legal, sin embargo, también se ha vuelto un campo de disputa para evitar el avasallamiento de los derechos. Son varios los casos donde comunidades, organizaciones y pobladores han utilizado normas provinciales nacionales e internacionales, y amparos judiciales para prohibir la práctica del fracking. En este sentido, el ámbito legal se despliega como un campo privilegiado de tensiones (Rodríguez Garavito, 2012), donde convive la suspensión de garantías y derechos constitucionales y democráticos, con herramientas y normativas apropiadas por distintos colectivos y por las poblaciones, que ayudan a frenar y/o retrasar el avance de estos proyectos sobre distintos territorios. Por ende, la actividad petrolera en la Cuenca Neuquina suele desenvolverse en un marco de excepción, donde las garantías constitucionales pueden quedar momentáneamente suspendidas en aras del desarrollo de algún emprendimiento considerado de interés estratégico por el Estado nacional (Arach, 2015).

El tercer plano, el de los impactos ambientales, ha sido ampliamente documentado, denunciado y analizado, no sólo en los proyectos de fractura hidráulica en Argentina, sino también en los EEUU, cuna de estas explotaciones. Los proyectos y estudios de impacto oficiales en Argentina tienden a ser cautelosos, estableciendo que si la explotación se realiza de manera adecuada, no habrá mayores conflictos ni problemas ambientales, y que el margen de error sería mínimo. Sin embargo, dichos informes no remarcan el carácter experimental de dicha técnica, ni la falibilidad humana que puede generar desastres ambientales y afectar los suelos, las napas freáticas, el aire y la salud pública. Tampoco tienen en cuenta los múltiples desplazamientos de otras actividades económicas, la expulsión de comunidades de sus tierras ancestrales que genera la actividad hidrocarburífera, los impactos urbanos en el paisaje local, ni mucho menos los debates por la utilización del agua y del 
suelo. Los conflictos por los basurales que tratan desechos de la actividad petrolera en la ciudad de Neuquén, han suscitado la movilización de distintos colectivos socioambientales que buscan su traslado a un ecoparque que permita sacar del ejido urbano el material contaminante que se encuentra en las inmediaciones de la periferia de la ciudad de Neuquén. Dichos basureros se encuentran cercanos a asentamientos urbanos que han sufrido las consecuencias de los desbordes de desechos, ya que las instalaciones han visto sobrepasada su capacidad de tratamiento debido a la falta de planificación y la vertiginosidad de la actividad hidrocarburífera iniciada en el 2012, aunque también ha sido denunciada la misma actividad por la quema de los desechos del petróleo (Declaración de la Comisión Fuera Basureros Petroleros, 10 de julio de 2016). Así, vemos que la cuestión del peligro ambiental está presente, y que desborda o se deslocaliza del lugar puntual donde se realiza la actividad petrolera.

\section{Matrices productivas en disputa en el Alto Valle de Rio Negro. Transformaciones territoriales en la ciudad de Allen}

Si bien la situación de la provincia de Río Negro posee ciertas similitudes con la de Neuquén, por ser la misma cuenca hidrocarburífera y por las políticas públicas nacionales, su alcance geográfico y productivo es de menor envergadura. Con varios intentos frustrados previos, desde los años sesenta la explotación petrolera se focalizó en el noroeste de la provincia. Al momento de indagar en la tensión por el uso del espacio rural, debido a las incidencias de nuevas actividades no agropecuarias en el área, es interesante analizar cómo una serie de transformaciones que se van dando en un frente frutihortícola van haciendo lugar a la llegada de la explotación de HRNC en el municipio de Allen, en la provincia de Río Negro. El territorio en donde se encuentra el municipio, en el departamento de General Roca, se caracteriza por ser una zona de transición entre el clima templado y el semiárido, en el cual los suelos fértiles y la disponibilidad hídrica son una característica de este ecosistema, condiciones que ofrecen recursos de una gran potencialidad productiva. La agricultura se extiende sobre los valles inferiores de los ríos Limay y Neuquén, y el valle superior del río Negro, comprendiendo una superficie aproximada de 100.000 hectáreas, de las cuales tres cuartas partes pertenecen a la provincia de Río Negro y el resto a la provincia del Neuquén. La zona se caracteriza por una marcada especialización en el uso del suelo y concentra el 83\% de la superficie implantada con frutales de pepita en la Patagonia Norte, el 82\% de manzanas y el 85\% de peras (CNA, 2002). En la región, los procesos por los que se dio la apropiación diferencial del suelo y su incorporación al mercado de tierras, han consolidado durante el siglo XX una matriz productiva inicial de tipo farmer. En este sentido, el término chacarero alude a un productor que tradicionalmente combinó la propiedad de un pequeño monte frutal, el trabajo familiar y el uso de trabajadores transitorios y permanentes.

La actividad hidrocarburífera en la zona del Alto Valle de Río Negro (AVRN) tiene inicio en 1960 con las exploraciones de YPF. El área Yacimiento Estación Fernández Oro (YEFO), ubicado en la ciudad de Allen, es la más importante de la provincia de Río Negro. La empresa Apache, inaugurada en el 2001 y con su casa matriz en Houston, comenzó la perforación de pozos no convencionales en el 2012 para extraer tight gas, con el uso fracking en Allen sobre la formación geológica Las Lajas. En aquel momento, el gobierno nacional mantenía fijo el USD 2,50 por millón de BTU. El precio del gas en boca de pozo para la empresa, la enorme inversión que demandaban 
estas locaciones en Allen, sumado a los escasos dividendos remitidos a la casa matriz en el 2009, fue convenciéndola de ponerla en venta. Un suceso particular se registró luego de la compra del 51\% de los activos de YPF por el Estado, cuando el gobierno nacional anunció que las petroleras que aumentaran en el 2013 su producción de gas respecto del 2012 recibirían por el volumen “incremental” el triple de precio, USD 7,50 por millón de BTU. Lo que para YPF y otras petroleras resultó ser una medida que hacía rentable la producción de arcilla y arenas compactas en Argentina, fue una política que no favoreció a la empresa Apache por su elevada producción del 2012, conllevando a que en febrero del 2014 YPF concretara la compra de los activos de Apache en la cuenca neuquina, incluidos Vaca Muerta y los pozos de tight gas en Allen.

En la periferia de la ciudad de Allen, el avance de la frontera hidrocarburífera se explaya en presiones sobre el territorio frutihortícola. La reducción de las tierras productivas, y la consolidación de tendencias rentistas por parte de los pequeños chacareros, es un indicador de los impactos indirectos que se registran. 11 Este proceso se viene desarrollando en un contexto productivo donde las políticas estatales y de mercado han condicionado las prácticas de los productores de los estratos más endebles de la cadena de producción.

La mayor presencia de las petroleras para la explotación de tight gas desde el 2012 viene consolidándose como un fenómeno que profundiza el abandono de una forma de organización tradicional de la actividad productiva. El área registra locaciones de pozos ubicados en las chacras, condicionando a los pequeños y medianos productores inferiores a 25 ha. Afectando mayormente a estratos que van de 5 a 10 ha, los productores se ven condicionados y tentados al alquiler o venta de sus chacras, acordando con la empresa petrolera YSUR-YPF una parte del área de sus tierras (entre 1 y 1,5 ha) para destinarlas como locación a la explotación petrolera, a través de contratos anuales o bianuales.

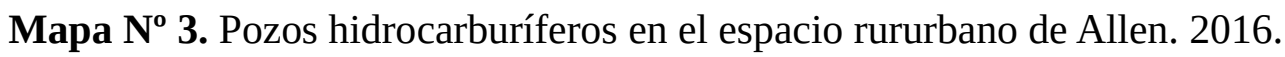

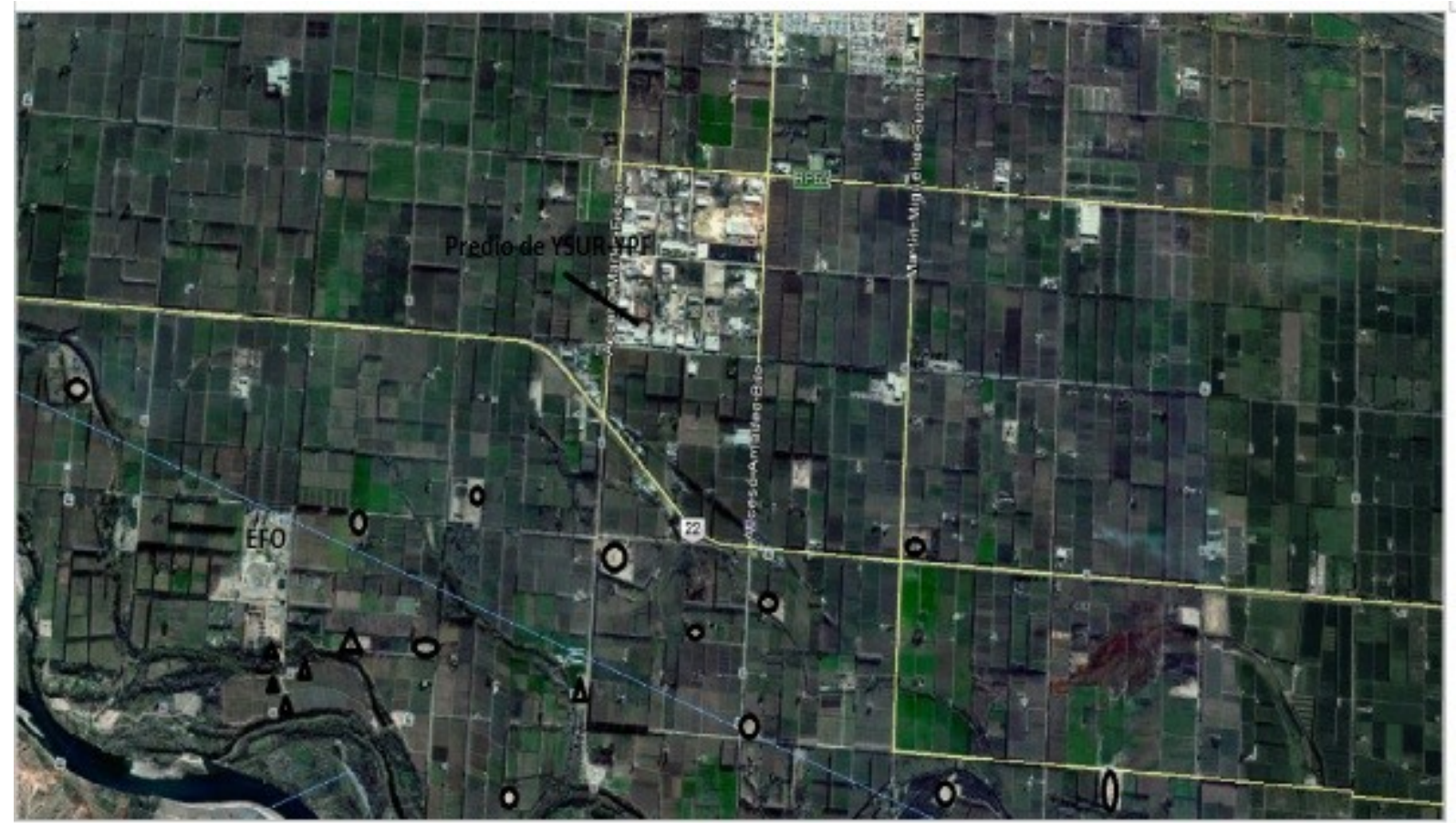


Iconos Triangulares: Señala las locaciones con pozos hidrocarburíferos convencionales desde el 2003.

EFO: Yacimiento Estación Fernández Oro. Planta de almacenamiento y procesamiento. Íconos circulares: Señala las locaciones con pozos hidrocarburíferos no convencionales entre 2012-2016.

Fuente: Elaboración propia con el uso del Google Earth.

En relación a las opiniones de los chacareros acerca de la presencia de las petroleras dentro de las chacras, se registran casos de propietarios de tierras que están alquilando hectáreas a YSUR-YPF y que consideran que ambas actividades son compatibles. El alquiler de hectáreas viene siendo un fenómeno que aumenta, principalmente en rangos de tamaño pequeño y mediano que no encuentran estímulos para seguir trabajando sus predios. Por otro lado, se identifican opiniones que parecen preocupar a los productores en relación a los protocolos de distintas certificadoras de fruta, que habilitan la comercialización interna y externa de la fruta.

Por ejemplo, las torres de luz, las torres que iluminan los pozos, traen la mosca y esta zona tiene que ser libre de mosca, que se llama carpocapsa. Entonces por ahí, en una trampa de chacra (nosotros tenemos todas las chacras cercas de algún pozo petrolero) hay 30 o 40 trampas, en las trampas hay carpocapsa. Entonces ¿qué pasa? vienen SENASA y te da de baja esa chacra para poder exportar a Brasil, te cierra un mercado. Chacarero José Roberto Gómez con 15 ha en producción Allen, 14 de diciembre de 2015.

En este marco, podemos destacar dos protocolos relevantes, la EurepGAP que abarca los aspectos relacionados con los peligros fitosanitarios, y el vinculado con el riesgo microbiano en los alimentos (Usgap). Se trata de certificados internacionales para asegurar calidad y seguridad en los alimentos, minimizar los impactos ambientales, reducir el uso de agroquímicos y optimizar la utilización de agua y suelo. Hay que tener presente que los sistemas hídricos existentes en el AVRN permiten el riego necesario para las plantaciones frutales, las mismas fuentes de agua que son empleadas por la subsidiaria YSUR-YPF para enfriar, lubricar y extraer tierra de perforación en una primera fase y, más adelante, la inyección de agua presurizada.

Esa tierra, la alquilaste por un año, y perdiste 1 ha o 2 ha. Nunca se tendría que haber
dejado entrar a las petroleras, por zonas productivas, se dejó entrar, pero además, le
llueven ofrecimiento a las petroleras de chacareros que quieren alquilar su chacra...
Entonces es una culpa compartida. Chacarero Maximiliano Fernández con 25 ha
en producción Allen, 10 de diciembre de 2015 .

Para la explotación de HRNC se utilizan las rutas y caminos locales, como así también una importante extensión del territorio que luego ocupan los camiones emplazados. La actividad implica un importante empleo de la infraestructura periurbana, cuyos costos son absorbidos por el Estado. La producción de un pozo es a corto plazo (5 o 6 años), la rentabilidad y eficiencia de los pozos es baja (a diferencia de los convencionales que llegan a estar activos por más de 20 años), mientras 
que la perforación en las hectáreas es permanente en el tiempo, y tanto la instalación como el revestimiento sufren un deterioro progresivo con el tiempo (Caparroz, 2013).

El pozo perdura toda la vida, a parte cuando ellos te compran o te alquilan, le meten un metro y medio de calcáreo. ¿Con qué lo sacas después? Si eso se compacta -y eso es como un cemento- la tierra se echa a perder, después para sacarlo, te traen cientos, miles de camionadas ¿Con qué lo sacas? El día que se vayan y te devuelvan la tierra, ésta queda perdida. Chacarero Julio Hernández con 5.5 ha en producción Allen, 5 de diciembre de 2015.

Como los HRNC no están acumulados en trampas, sino que se encuentran muy dispersos, en cada yacimiento hay que explotar un volumen de roca mayor para obtener la misma cantidad de gas que en una explotación convencional. Por ende, las explotaciones deben ser más extensas e intensivas, lo cual da cuenta de un paisaje frutihortícola salpicado por locaciones con actividad hidrocarburífera. En este marco es posible encontrar, en el área rururbana de Allen, unidades de organización de la producción de perfil frutícola (manzanas y peras) reconvertidas según los parámetros de exigencias tecnológicas y productivas, y explotaciones agropecuarias marginales, alternando con fenómenos de neoruralidad, sin vinculación agropecuaria, que se hacen más frecuentes. Encontramos así un área con “tensión de territorialidades” (Porto Gonçalves, 2001), idea que instala precisamente la tracción entre matrices diferentes en cuanto al uso y apropiación del territorio: una declinante, la ligada a la actividad frutihortícola; la otra ascendente, ligada a los hidrocarburos.

\section{Reflexiones finales}

La explotación de los hidrocarburos no convencionales ha surgido en un contexto caracterizado por los cambios y las innovaciones tecnológicas. La "Revolución del Shale” en EE.UU, a principios del 2000, hizo rentable la apuesta por los no convencionales. Desde actores socioeconómicos energéticos y políticos dominantes se difunde un discurso que pregona la utilidad de los hidrocarburos, en tanto impulsor del progreso y desarrollo industrial para las potencias emergentes. El déficit energético causado por las políticas de los años noventa y catalizados por los patrones de consumo productivo, de transporte y de consumo de hogares en el siglo XXI en la Argentina, define una encrucijada: se continúa por el camino inercial trazado por los estilos de desarrollo conocidos, o se encara un proceso de transformaciones cuyos resultados visibles deben ser percibidos en plazos no lejanos. La confianza construida en torno a los procesos de extracción de HRNC está condicionada al precio internacional de los hidrocarburos. Mantener esa línea de explotación energética sólo es posible -en el actual contexto de mercado- sobre la base de grandes apoyos económicos, fiscales y de infraestructura provista por el Estado nacional y los Estados provinciales, sede de los yacimientos, a costa del diferimiento o cancelación de otro conjunto de necesidades sociales. Aun con precios compensatorios o que garanticen el equilibrio desde un punto de vista económico, la producción prometida de hidrocarburos mediante el fracking no permitirá resolver las urgencias de corto plazo existentes. La extracción de HCNC constituye una actividad intensiva en capital (no en trabajo) y demanda cantidades importantes de energía, agua y materiales (acero, cemento y arena, entre otros). De seguir expandiéndose, profundizará las transformaciones en la 
escala de la intervención territorial. La expansión del fracking, antes que resolver la dependencia de fuentes energéticas no renovables, la incrementa, demandando el empleo de enormes cantidades de energía fósil (tanto directa como indirectamente) difícilmente substituibles. A su vez, solucionar la problemática mencionada podría requerir que se realicen inversiones de energía fósil en alternativas más sostenibles. De esta manera, la explotación de HRNC comprende un despliegue de actividades que no podrían realizarse en base a energías renovables; el acero que demandan las tuberías, la inyección del fluido de fractura, la síntesis de productos químicos, el transporte de arena y los equipos de perforación, son insumos que remarcan la dependencia fósil en las actividades económicas. De mantenerse las tendencias actuales, tendríamos de manera predominante una generación térmica en base a combustibles fósiles con escasa participación de renovables en la matriz energética, profundizando las desigualdades en las regiones y acelerando los procesos de contaminación y degradación de los ecosistemas.

\section{Notas}

1 Por medio de entrevistas semiestructuradas de una muestra de 16 casos seleccionados por método de bola de nieve, y definidos por composición de estrato de un monte frutal de (0,5 a 25 ha), se buscó indagar el modo en que la operadora petrolera YSUR-YPF se vincula con los productores frutihortícolas locales en las distintas fases de planeamiento, ejecución y post-fracturas.

$\underline{2}$ Con hidrocarburos no convencionales nos referimos a las arenas bituminosas, petróleo y gas de pizarra o esquisto (shale gas y shale oil) y gas de arenas profundas/compactas (tight gas). La técnica del fracking, consiste en inyectar a altas presiones agua con un variado contenido de arena y químicos en las formaciones rocosas a fin de generar fracturas para extraer el gas o el crudo encerrado en ellas (Bertinat, D’ Elia, et al., 2014). A diferencia de los pozos convencionales, para llegar a las rocas que contienen en sus pequeños poros los recursos, es necesario realizar una perforación vertical, para luego avanzar horizontalmente y/o diagonalmentey romper la roca para que los hidrocarburos asciendan a la superficie.

$\underline{3}$ Los objetivos mencionados se pueden encontrar en el Prospecto Obligación Negociable Clase XXVIII.

4 Para llevar a cabo el convenio se creó un complejo entramado de compañías radicadas en paraísos fiscales que permiten que Chevron no figure. Por lo tanto, la concesión del área se reparte entre YPF S.A. y la Compañía de Hidrocarburos No Convencional Srl. Para ocultar a la firma norteamericana, en la documentación se deja constancia que se crearon las siguientes firmas: YPF Shale Oil Investment I e YPF Shale Oil Investment II en el estado de Delaware, EE.UU.; y Overseas Finance I en las Islas Bermudas (Mullally et al., 2017).

$\underline{5}$ Proveedoras de metalmecánica, electrónica y otros bienes y servicios integrados a la cadena de valor y vinculadas al mercado externo.

6 Se inició en el 2012 en el país y en el 2013 en la Cuenca Neuquina. Desde su comienzo se vincularon alrededor de 100 proveedores de bienes y servicios ubicados en distintas ciudades de Neuquén, Río Negro y La Pampa. 
Z Un ejemplo claro lo constituye el servicio automotor, el medio más importante de traslado en la cuenca. La mayor parte de los bienes e insumos se generan fuera de la región y los trabajadores del petróleo realizan cotidianos y extensos traslados. Asimismo, se viene perfilando desde las oficinas gubernamentales la necesidad de reactivar los tendidos ferroviarios para el desplazamiento de arena, tubing y maquinarias pesadas. Entre los diversos proyectos, sobresale la puesta en funcionamiento del ramal que une las localidades de Cipolletti y Barda del Medio con Añelo.

8 Añelo, en particular, creció de 2.689 habitantes en el 2010 a 6.000 en 2015.

9 Para pensar la planificación territorial de Añelo se incluyó a la localidad dentro del programa Iniciativa Ciudades Emergentes y Sostenibles (ICES), financiada por el Banco Interamericano de Desarrollo desde el 2010, y por la Fundación YPF.

10 Entre algunos puntos del acuerdo se propuso la eliminación del pago de las "horas taxi”, que contabilizaban el tiempo desde que el trabajador salía desde su hogar hasta que retornaba a él; se estableció un nuevo límite a la continuidad del trabajo según la velocidad de las ráfagas de viento (de 30 a $60 \mathrm{kms} / \mathrm{h}$ ) y se promovió la posibilidad de reubicación de trabajadores en tareas distintas a las consignadas inicialmente, entre otros.

11 En agosto de 2013, luego de la “pueblada” en Allen demandando la defensa de la matriz productiva y el cuidado del agua, se llevó a cabo la presentación de la ordenanza que prohibía el fracking en el ejido urbano por parte de APCA (Asamblea Permanente del Comahue por el Agua) al Concejo Deliberante de la ciudad. Tres meses después, la ordenanza fue declarada inconstitucional por el Tribunal Superior de Justicia provincial, quien argumentó que no eran facultades de los municipios legislar en materia de hidrocarburos, ya que los mismos son recursos provinciales y, por lo tanto, la potestad pasaba por autoridades de la provincia de Río Negro.

\section{Bibliografía}

-Arelovich, S., Bertinat, P., Arelovich, L. y García, G. (2015). Fracking. Tensión entre lo estatal, lo público, lo privado y el futuro energético. Rosario: Taller Ecologista.

-Arach, O. A. (2015). Guerreros del antropoceno. Movimientos societales frente a la expansión destructiva. Athenea Digital, 15(4), 255-266.

-Álvaro, M. B. (2013). Estrategias de reproducción social en la producción familiar capitalizada, los chacareros del Alto Vallen de Rio Negro. Buenos Aires: Editorial La Colmena.

-Bertinat, P., D' Elia, E., OPSur., Ochandio, R., Svampa, M. y Viale, E. (2014). 20 Mitos y realidades del fracking. Buenos Aires: Editorial El colectivo.

-Caparroz, M. J. (2013). Repercusiones territoriales de la fractura hidráulica o "fracking”. En Cantabria, Burgos y Palencia. Los Permisos de Investigación Bezana y Bigüenzo [No publicado]. Recuperado de la web en: http://eprints.ucm.es/23795/ 
-Di Filippo, A., y Jadue, S. (1976). La Heterogeneidad Estructural: concepto y dimensiones. El Trimestre Económico, 43(169), 167-214.

-De Jong, M. G. (2010). La fruticultura patagónica del Alto Valle. Buenos Aires: Editorial La Colmena.

-Escobar, A. (1997). Cultural politics and biological diversity: state, capital, and social movements in the Pacific Coast of Colombia. En Lisa Lowe and David Lloyd (Eds.), The Politics of Cul -ture in the Shadow of Capital. Duke University Press Durham.

-Fernández, R. (2015). Escenarios Energéticos 2015-2035: resumen y conclusiones para un futuro energético sustentable. Buenos Aires: Fundación AVINA.

-Barros, S. (2012). En Comodoro el mercado funciona y sin embargo no se puede pensar en una sociedad integrada. Panorama Universitario, II (13). Disponible en: http://www.unp.edu.ar/panorama/NOVIEMBRE\%202012.pdf

-García, F. (2011). Manual de estadísticas energéticas. Quito: OLADE. Disponible en: http://biblioteca.olade.org/opac-tmpl/Documentos/old0179.pdf

-Goldstein, E., Kulfas, M., Margulis, D. y Zack, G. (2016). Efectos macroeconómicos del sector energético en la Argentina en el período 2003-2014. Realidad Económica No 298, 32-52.

-Gudynas, E. (2004). Ecología, Economía y Ética del Desarrollo Sostenible. Montevideo: Editorial Coscoroba.

-Gudynas, E. (2009). Diez tesis urgentes sobre el nuevo extractivismo. En Schuldt, J., Acosta, A., Barandiarán, A., Bebbington, A., Folchi, M., CEDLA, ... Gudynas, E. Extractivismo, Política y Sociedad. Quito: CAAP Y CLAES,187-225 Disponible en: http://www.rosalux.org.ec/attachments/article/497/extractivismo.pdf

-Gudynas, E. (2011). Desarrollo, extractivismo y buen vivir. Debates sobre el desarrollo y sus alternativas en América Latina: Una breve guía heterodoxa. En Lang, M. y Mokrani, D. (comp.) "Más allá del desarrollo”, Grupo Permanente de trabajo sobre Alternativas al Desarrollo. Quito: Fundación Rosa Luxemburg/Abya Yala, 21-55. Disponible en: http://rio20.net/wpcontent/uploads/2012/07/mas-alla-del-desarrollo 30.pdf

-Guzowski, C. (2016). Los desafíos de la política energética Argentina. Panorama y propuestas. CABA: Editorial Dunken.

-Honty, E. (2013). Energía en las transiciones. En Hidalgo María Eugenia y ElbersJoerg (Ed.), Ecuador: ¿Estamos en transición hacia un país pospetrolero? Ecuador: CEDA.

-Honty, E. (2014). Límites de las energías renovables. Debate, 92.

-Lander, E. (1993). Ciencias sociales: saberes coloniales y eurocéntricos. En Edgardo Lander (comp.), La colonialidad del saber: eurocentrismo y ciencias sociales. Perspectivas latinoamericanas. Buenos Aires: CLACSO. 
-Landriscini, S., G. y Robles L. V. (2016). Gestión del conocimiento, mejoras internas y vínculos externos en PyMES de hidrocarburos de la cuenca neuquina. Presentado en el segundo congreso de CAESCYT (2016). Bariloche, UNRN.

-Martínez Alier J. (2004). Los Conflictos Ecológico-Distributivos y los Indicadores de Sustentabilidad. Revista Iberoamericana de Economía Ecológica, 1.

-Miranda, O. (1995). El cambio técnico en la Agricultura Familiar del Alto Valle de Río Negro. Revista RURALIA, 1(6), 28-46.

-Mullally, M. A., Revolich, A. L., Cabrera, F. y Di Risio, R. (2017). Megaproyecto Vaca Muerta. Informe de externalidades. Buenos Aires: DosRios. Disponible en: http://www.estudiodosrios.com.ar/?p=1128

-Observatorio Petrolero Sur (2017). "Vaca Muerta, un megaproyecto que se extiende.”

Recuperado de: http://www.opsur.org.ar/blog/2017/04/25/el-megaproyecto-vaca-muerta-unapropuesta-de-intervencion/

-Observatorio Petrolero Sur (2015). Alto Valle Perforado. El petróleo y sus conflictos en las ciudades de la Patagonia Norte. Buenos Aires: Edición Jinete Insomne.

-Prebisch, R. (1949). El desarrollo económico de la América Latina y algunos de sus principales problemás. CEPAL - Naciones Unidas, 63.

-Pinto, A. (1968). Naturaleza e implicaciones de la "Heterogeneidad Estructural” de la America Latina. En Lara Beautell (ed.), Dos Polémicas sobre el Desarrollo de América Latina: Textos del Instituto Latinoamericano de Planificación Económica y Social. Santiago: Universitaria y en.El Trimestre Económico $\quad \mathrm{N}^{\circ}$ 145, 83-100. Disponible en: http://www.rrojasdatabank.info/pinto/apintohet.pdf

-Porto Gonçalvez, C. W. (2001). Geo-grafías. Movimientos sociales, nuevas territorialidades y sustentabilidad. México: Siglo XXI.

-Ramos, P. (2012). ¿En qué consiste la fractura hidráulica? En Cotarello, Pablo (coord.), Agrietando el futuro. La amenaza de la fractura hidráulica en la era del cambio climático. Madrid: Editorial Libros en Acción.

-Recalde, M. (2011). Sistemas energéticos, mercado y Estado: el rol de los recursos naturales energéticos y la política energética en el caso argentino. Madrid: Editorial Académica Española.

-Recalde, M. (2016). Una visión integral del sector energético argentino: de las causas a las consecuencias de la ausencia de política energética de largo plazo. En Guzowski, C, Martín Ibañez. M. M y Rojas, L. M (comp), Los desafíos de la política energética argentina. Panorama y Propuesta. CABA.: Editorial Dunken.

-Rodríguez Garavito, C. (2012). Etnicidad.gov Los recursos naturales, los pueblos indígenas y el derecho a la consulta previa en los campos sociales minados. Bogotá: Centro de Estudios de Derecho, Justicia y Sociedad, Dejusticia. 
-Santos, M. (1995). Metamorfosis del espacio habitado. Barcelona: Editorial Oikos - Tau.

-Schweitzer, F. (2014). Patagonia, naturaleza y territorios. Geograficando, 10(2).

-Svampa, M. (2011). Modelo de desarrollo y cuestión ambiental en América Latina: categorías y escenarios en disputa En Wanderley, F. (comp.), El desarrollo en cuestión. Reflexiones desde América Latina. La Paz: Editorial Plural, Oxfam y CIDES-UMSA.

-Svampa, M. (2012). Pensar el desarrollo desde América Latina. En Massuh, G. (ed.), Renunciar al bien común: extractivismo y (pos) desarrollo en América Latina. Buenos Aires: Editorial Mardulce.

-Svampa, M. (2013). Consenso de los Commodities y lenguajes de valoración en América Latina. Nueva Sociedad, 244.

-Svampa, M. y Viale, E. (2014). Maldesarrollo. La Argentina del extractivismo y el despojo. Buenos Aires: Ediciones Katz.

-Svampa, M. (2016). El Antropoceno, un concepto que sintetiza la crisis civilizatoria. La izquierda diario. Recuperado de:_http://www.laizquierdadiario.com/ElAntropoceno-un-concepto-que-sintetiza-la-crisis-civilizatoria

-Tagliabue, C. (2013). La actual naturaleza jurídica de YPF S.A. y sus implicancias jurídicas. En Acuña, E.,T. ... [et.al.]; prólogo de Spota, A.,A. Estudios de Derecho Público. Buenos Aires: Asociación de Docentes. Disponible en: http://www.derecho.uba.ar/docentes/pdf/estudios-dederecho/008-edp-alvarez-tagliabue.pdf

\section{Fuentes gubernamentales e informes oficiales:}

-Subsecretaría de Planificación Territorial de la Inversión Pública de la Nación. (2014). “Estudios Estratégicos para el Desarrollo Territorial de la Región VacaMuerta. Primera etapa. Informe síntesis”. Disponible en: http://studylib.es/doc/8580050/primera-etapa---ministerio-de-energ \%C3\%ADa-y-miner\%C3\%ADa

-Subsecretaría de planificación territorial de la inversión pública (2015). “Estudios estratégicos para el desarrollo territorial de la región Vaca Muerta. Segunda etapa programa de fortalecimiento institucional. Informe final, Tomo 1.

-Ministerio de Energía y Minería de la Nación (2016). Documento metodológico del Balance Energético Nacional 2015: Disponible en: http://www.energia.gob.ar/contenidos/archivos/Reorganizacion/informacion del mercado/publicaci ones/energia en gral/balances 2016/documento-metodologico-balance-energetico-nacional-final2015.pdf

-Colegio de Arquitectos de Neuquén (2014). Plan de desarrollo para Añelo. Disponible en: http://www.canqn.org.ar/wp-content/uploads/2014/06/INFORME-A\%C3\%91ELO.pdf 


\section{Entrevista consultada:}

-Entrevista No 7 a chacarero de 58 años. Entrevistado: José Roberto Gómez. Entrevistador: Fernando Svampa. Lugar: Allen-Río Negro. Día: 14 de diciembre de 2015. Hora: 14:16hs.

-Entrevista No 12 a chacarero de 42 años. Entrevistado: Maximiliano Fernández. Entrevistador: Fernando Svampa. Lugar Allen- Río Negro. Día: 10 de diciembre de 2015, 19:19hs.

-Entrevista ํ15 a chacarero de 67 años. Entrevistado: Julio Hernández. Entrevistador: Fernando Svampa. Lugar: Allen-Río Negro. Día: sábado 5 de diciembre de 2015. Hora: 16:35hs 